\title{
A Candida albicans RAS-related gene (CaRSR1) is involved in budding, cell morphogenesis and hypha development
}

\author{
Liora Yaar, Moshe Mevarech and Yigal Koltin† \\ Author for correspondence: Yigal Koltin. Tel: +1 6177616804 . Fax: +1 6176797467. \\ e-mail: koltin@mpi.com
}

Department of Molecular Microbiology and Biotechnology, Faculty of Life Sciences, Tel Aviv University, Tel Aviv 69978, Israel

\begin{abstract}
Candida albicans, the most important human fungal pathogen, is a dimorphic fungus that can grow either as a yeast or as a hyphal form in response to medium conditions. A RAS-related C. albicans gene (CaRSR1) was isolated as a suppressor of a cdc24ts bud-emergence mutation of the baker's yeast, Saccharomyces cerevisiae. The deduced protein encoded by CaRSR1 is 248 amino acids long and $56 \%$ identical to that encoded by the $S$. cerevisiae RSR1 (BUD1) gene. Disruption of CaRSR1 in C. albicans indicated that CaRSR1 is involved in both yeast and hypha development. In the yeast phase, CaRSR1 is required for normal (polar) bud site selection and is involved in cell morphogenesis; in the yeast-mycelial transition it is involved in germ tube emergence; and in the development of the hyphae it is involved in cell elongation. The disruption of CaRSR1 leads to reduced virulence in both heterozygote and homozygote disruptants in a dose-dependent manner. The reduced virulence can be attributed to the reduced germination and shorter hyphae resulting from the disruption of CaRSR1.
\end{abstract}

Keywords: C. albicans morphogenesis, RSR1, BUD1, GTPase, yeast bud site selection

\section{INTRODUCTION}

Candida albicans is the most important fungal pathogen in humans. The organism is diploid and lacks a known sexual cycle. It is dimorphic and grows in a yeast or hyphal form in response to environmental conditions. In response to an external signal, the cells of the yeast phase form a germ tube which subsequently evolves into a hypha. During pathogenesis, this transition may play a role in the progression of the disease state (Cutler, 1991). The pattern of bud formation in the yeast phase is also regulated. The pattern of bud site selection is affected in a distinct way by environmental conditions. As an example, buds emerge primarily at one pole of the mother cell when cells are grown at $23-28^{\circ} \mathrm{C}$ and $\mathrm{pH} 7 \cdot 4$. However, when cells are grown at $37^{\circ} \mathrm{C}$ and $\mathrm{pH} 4.5$ the bud sites are not adjacent to previous bud sites and are scattered over the entire cell surface (Chaffin, 1984). Selection of sites for germ tube forma-

†Present address: Millennium Pharmaceuticals, Inc., 640 Memorial Drive, Cambridge, MA 02139, USA.

Abbreviation: 5-FOA, 5-fluoroorotic acid.

The GenBank accession number for the sequence reported in this paper is U46158. tion, which seemed random, was suggested to be under different regulation. Cell wall expansion during growth of C. albicans is also regulated (Staebell \& Soll, 1985). The apical zone accounts for the first two-thirds of surface expansion of bud growth, which is then shut down and followed by a more general pattern of cell wall expansion. During mycelial growth, at least $90 \%$ of cell wall expansion is due to growth in the apical zone.

Many of the genes associated with bud site selection and polarized growth in Saccharomyces cerevisiae have been identified. They are known to affect specifically either the orientation or the assembly of the polarity axis (for reviews see Mischke \& Chant, 1995; Roemer et al., 1996). These include bud site selection genes RSR1 (also known as BUD1) to $B U D 9$, and the polarity-establishing genes $C D C 24, C D C 42, C D C 43$ and $B E M 1$. The latter group of genes is also required for bud formation and viability. Rsr1 is a Ras-related GTPase required for normal bud site selection in both haploid and diploid $S$. cerevisiae cells. Deletion of S. cerevisiae RSR1 (ScRSR1) causes randomization of bud position (Bender \& Pringle, 1989). It has been suggested that in S. cerevisiae, the RSR1 GTPase cycle links spatial bipolar signals to polarity establishment functions (Zheng et al., 1995). 
Since the two phases of growth of C. albicans, yeast phase and filamentous phase, require polar development, the possibility of a common pathway was intriguing. This study intended to determine whether the yeast and hyphal phases share a common development pathway. The C. albicans functional homologues of $S$. cerevisiae polarity establishment genes are the natural candidates for genes involved in polar budding, and therefore are candidates for involvement in filamentous growth. In this study, we intended to isolate either one of the polarity-establishing homologues of $S$. cerevisiae or bud site selection homologues and to test the effect of these genes on yeast and hypha development in C. albicans. A C. albicans gene was isolated as a suppressor of an S. cerevisiae $c d c 24^{\text {ts }}$ mutation. Based on its nucleotide sequence and motif analysis it was found to be similar to ScRSR1. We show that CaRSR1 is required to restrict the buds of the yeast phase to the cell poles and is involved in cell morphogenesis, germ tube emergence and hypha growth. The results obtained identify CaRSR 1 as a gene involved in both the yeast and hyphal phases. The gene is not essential but disruption of this gene in C. albicans affects significantly the virulence of the pathogen.

\section{METHODS}

Yeast strains, media and methods. The $S$. cerevisiae strains used were: TD4 (MATa ura3-52 his4-519 leu2-3,112 trp1 can1; G. Fink, Whitehead Institute, Cambridge, USA); KGC24-3 (MAT $\alpha$ cdc24-4 ${ }^{\text {ts }}$ ura3-52 his4 leu2-3,112 trp1-284; Coleman et al., 1986); and DJTD2-16D (MAT $\alpha c d c 42-1^{\text {ts }}$ ura3 his4 leu2 trp1 gal; Bender \& Pringle, 1989). The C. albicans strains used are listed in Table 1. YPD, SD and SC media for S. cerevisiae (Sherman, 1991) were used for growth of $S$. cerevisiae and C. albicans. When including leucine in SD or $\mathrm{SC}$, its concentration was modified to $100 \mathrm{mg} \mathrm{l}^{-1}$. Lee medium (Lee et al., 1975) adjusted to $\mathrm{pH} 7.2(1.5 \%$, w/v, agar for plates) was used for growth and for yeast-hypha transition assays. Serum (foetal calf) Sabouraud medium (Biological Industries) and $3 \%$ Sabouraud medium (Difco; $1: 1, \mathrm{v} / \mathrm{v}$ ) were used for yeast-hypha transition assays (Kwon-Chung \& Bennett, 1992). S. cerevisiae and C. albicans transformations were performed by the LiAc procedure (Ito et al., 1983). Approximately $5 \mu \mathrm{g}$ DNA was used for each $C$. albicans transformation. SC solid medium devoid of uracil was used for selection of $C$. albicans $\mathrm{Ura}^{+}$transformants. Selection of $\mathrm{Ura}^{-}$C. albicans auxotrophs was performed on medium containing 5-fluoroorotic acid (5-FOA) according to Boeke et al. (1984), except that uracil was replaced by $25 \mu \mathrm{g}$ uridine $\mathrm{ml}^{-1}$.

Budding pattern determination. C. albicans cells were grown exponentially for at least nine generations in SC-uracil medium with agitation at $30^{\circ} \mathrm{C}$ to a final cell density of $1 \cdot 2-3.7 \times 10^{6}$ cells $\mathrm{ml}^{-1}$. The cells were washed with deionized water, suspended in $0.1 \mathrm{mg}$ Calcofluor White M2R ml $\mathrm{m}^{-1}$ (Sigma fluorescent brightener 28) for staining of bud scars (Maeda \& Ishida, 1967) and observed by fluorescence microscopy. Cells that had budded at least twice (represented by the total number of bud scars, buds and unseparated daughter cells) were scored for bud site location. Cell poles were defined for this experiment as the two extreme thirds of the cell length. For spherical cells where the cell poles were not easily identified (CAI4-5 strain), the pole was defined as the third of the cell proximal or distal to the mother cell. When a spherical cell was not attached to its mother cell, it was scored only if it had already budded at least three times. Spherical cells that had budded twice and were not attached to a mother cell were not scored. They comprised less than $5 \%$ of the cells that had budded at least twice.

\section{Germ tube formation induction}

Lee medium at $37^{\circ} \mathrm{C}$. C. albicans cells from SC-uracil plates were spread on Lee medium plates and incubated at $26{ }^{\circ} \mathrm{C}$ for $2 \mathrm{~d}$. Cells were suspended in deionized water, and kept on ice while being counted. Lee broth $(20 \mathrm{ml})$ in a $125 \mathrm{ml}$ glass flask was inoculated with cells to an initial density of 2.3-3.8 $\times 10^{6}$ cells $\mathrm{ml}^{-1}$, and agitated in a gyratory water-bath shaker (New Brunswick G76) at $36.5^{\circ} \mathrm{C}$. Each $200 \mu \mathrm{l}$ sample was supple-

Table 1. C. albicans strains

\begin{tabular}{|c|c|c|c|}
\hline Strain & Parent & Genotype & Source/reference \\
\hline SC5314 & & & Gillum et al. (1984) \\
\hline CAF2-1 & SC5314 & $\Delta u r a 3:: i m m 434 / U R A 3$ & Fonzi \& Irwin (1993) \\
\hline CAI4 & CAF2-1 & $\Delta u r a 3:: i m m 434 / \Delta u r a 3:: i m m 434$ & Fonzi \& Irwin (1993) \\
\hline CAI4-10 & CAI4 & 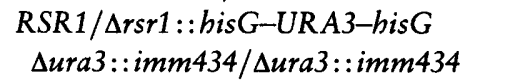 & This work \\
\hline CAI4-11 & CAI4-10 & 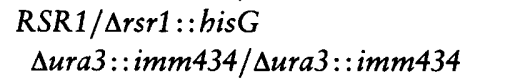 & This work \\
\hline CAI4-5 & CAI4-11 & 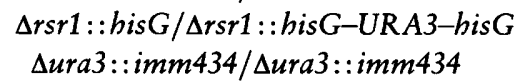 & This work \\
\hline CAI4-5a & CAI4-5 & $\begin{array}{l}\Delta r s r 1:: \text { his } G / \Delta r s r 1:: \text { his } G \\
\quad \text { Aura3::imm } 434 / \Delta u r a 3:: i m m 434\end{array}$ & This work \\
\hline CALY5a1 & CAI4-5a & 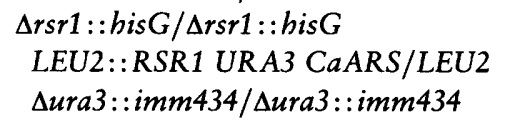 & This work \\
\hline CALY5a20 & CAI4-5a & 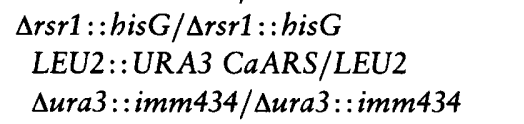 & This work \\
\hline
\end{tabular}


mented with $20 \mu \mathrm{l} \mathrm{SDS/formalin} \mathrm{fixative} \mathrm{(Odds} \mathrm{et} \mathrm{al.,} \mathrm{1985).}$ Samples were kept for subsequent microscopic observation. At least 200 yeast cells from each sample were counted, monitoring the ratio of yeast cells having germ tube(s)/ hyphae.

Serum medium. Cells were grown overnight in YPD at $30^{\circ} \mathrm{C}$, then inoculated into test tubes containing serum and Sabouraud medium (1:1) and incubated without shaking at $37^{\circ} \mathrm{C}$. Cells were sampled for $85 \mathrm{~min}$ after inoculation and fixed with $\mathrm{SDS} /$ formalin. At least 450 cells of each strain were examined microscopically to detect germ tube formation.

Virulence tests. To test the importance of CaRSR1 in virulence, immunocompetent and neutropenic 4-week-old male mice (Harlan-Sprague-Dawley) were used. The mice were caged and fed according to National Institutes of Health guidelines for ethical treatment of animals. The C. albicans strains tested were grown in YPD medium overnight at $37^{\circ} \mathrm{C}$, washed twice in saline and resuspended to a concentration of $10^{7}$ cells $\mathrm{ml}^{-1}$ as determined by cell count. Infection was performed via the lateral tail vein. Immunocompetent mice were infected with $10^{6}$ cells per mouse. Cyclophosphamide (150 mg kg-1) was used to induce neutropenia by an intraperitoneal administration of the drug $1 \mathrm{~d}$ prior to the infection and $3 \mathrm{~d}$ post-infection. The neutropenic mice were infected with $10^{4}$ cells per mouse.

Nucleic acid methods. Standard recombinant DNA techniques (Sambrook et al., 1989) were followed. Plasmid DNA was extracted using the Qiagen plasmid purification kit. A Sequenase 2.0 kit was purchased from United States Biochemical and used according to the manufacturer's directions for chain-termination DNA sequencing (Sanger et al., 1977). Oligonucleotides were synthesized by BioTechnology General. Analysis of CaRSR1 DNA and deduced protein sequences was assisted by either DNA Strider (Marck, 1988) or the University of Wisconsin Genetics Computer Group software package (Devereux et al., 1984). For Southern blot analysis, C. albicans strains were grown in YPD and genomic DNA was prepared according to Hoffman \& Winston (1987). Digested DNA was blotted onto Hybond-N + membrane (Amersham) and hybridized with a digoxigenin-dUTP (Boehringer Mannheim)-labelled DNA probe and detected by chemiluminescence (CSPD; Boehringer Mannheim). Escherichia coli $\mathrm{DH} 5 \alpha$ was used as a host for amplification of plasmids. Strain NS2626 (dam13::Tn9; Sternberg et al., 1986) was used for amplification of pLY006.

Construction of the disruption vector for C. albicans. Plasmid pLY005 (Fig. 5) was used as a template for PCR-derived deletion. The primers used were 5'CAATTAATGATCACCCAAAGTCTAGCTCAGGAAGC, identical to the $(+)$ strand in the region of the BclI site, and 5'GGCGCTGATCATCGGTGACAGAGTACACCAATAAGAACCC, which introduces a new $B c l I$ site, connected to a sequence identical to the (-) strand, $441 \mathrm{bp}$ upstream of the existing site. PCR amplification therefore yielded a $7 \cdot 1 \mathrm{~kb}$ fragment of pLY005 lacking $441 \mathrm{bp}$ (encoding residues $87-233$ of CaRsr1). This fragment was extracted from an agarose gel, digested with $B c l$ (to remove the ends) and self-ligated to yield pLY006. The disruption vector was constructed by using a cassette (Fonzi \& Irwin, 1993) of Salmonella typhimurium bis $G$ gene direct repeats flanking a CaURA3 gene, cloned in plasmid pCUB6. The Bcll-linearized pLY006 was ligated to the $3.7 \mathrm{~kb} \mathrm{BamHI}-$ Bglll fragment of pCUB6 carrying the disruption cassette. The ligation product pLY007 was used as a source for the $5.4 \mathrm{~kb}$ SpeI-HindIII (Carsr1A::hisG-URA3-bisG) disruption fragment.
Construction of a CaRSR1 C. albicans/E. coli shuttle plasmid (pLY008). A $3.3 \mathrm{~kb}$ HindIII-HindIII fragment of pLY001 (CaRSR1) was ligated to the HindIII unique site in the polylinker of pCA-I. pCA-I (from William Fonzi, Georgetown University, USA) is a modified version of pRC2312 [pUC9 sequences (bla, ori and lacZ), and C. albicans URA3, CaARS and LEU2; Cannon et al., 1990] in which a multiple cloning site adaptor has been inserted.

\section{RESULTS}

\section{Isolation of a C. albicans suppressor of an $S$. cerevisiae coc24 mutation}

In a search for genes regulating polarized growth of $C$. albicans, efforts were conducted to isolate the $C$. albicans functional homologue of $S$. cerevisiae CDC24. A C. albicans genomic library cloned in a high-copynumber plasmid (Rosenbluh et al., 1985) was used to transform an $S$. cerevisiae cdc24 $4^{\text {ts }}$ mutant (KGC24-3). Cells were plated on SD agar supplemented with uracil, histidine and tryptophan and incubated at $24^{\circ} \mathrm{C}$ to select $\mathrm{Leu}^{+}$transformants. The plates were then replicated onto YPD supplemented with $1 \mathrm{M}$ sorbitol agar and incubated at a non-permissive temperature of $36^{\circ} \mathrm{C}$. This procedure allowed isolation of a functional homologue of ScCDC24 or multicopy suppressors of this gene. Sorbitol supplementation has been shown to facilitate the isolation of multicopy suppressors of this Sccdc24 $4^{\text {ts }}$ mutation (Bender \& Pringle, 1989). Several colonies were isolated and the linkage of the suppression of the temperature-sensitive phenotype of $S c c d c 24$ to the transforming plasmids was confirmed. One of the isolated plasmids, pTM1861, was further studied and subjected to subcloning in the $S$. cerevisiae/E. coli highcopy-number shuttle vector pRS426 (Christianson et al., 1992; Fig 1). To identify the DNA fragment encoding the gene that suppresses $S c c d c 24^{\text {ts }}$, each subclone was used to transform the $S$. cerevisiae mutant. Transformants were tested for growth at $36^{\circ} \mathrm{C}$ by plating drops of $1.3 \times 10^{3}$ cells onto duplicate SC agar plates supplemented with $1 \mathrm{M}$ sorbitol (Bender, 1993). The plates were incubated for $45 \mathrm{~h}$ at either $36^{\circ} \mathrm{C}$ or $24^{\circ} \mathrm{C}$. As a control, the suppression of $S c c d c 24^{\text {ts }}$ by $S$. cerevisiae RSR1 cloned in YEp24 (pPB117; Bender \& Pringle, 1989) was tested. No significant difference was noticed in the suppression of $S c c d c 24$ by either $S c R S R 1$ or the sequence cloned from C. albicans (data not shown).

\section{Effect of the $C$. albicans cloned DNA on the morphology of $S$. cerevisiae cdc42 mutant and wild- type strains}

$S$. cerevisiae genes which have been isolated as suppressors of a $c d c 24$ mutation are involved in cell morphogenesis (Bender \& Pringle, 1989; Herskowitz et al., 1995). To determine whether the cloned C. albicans sequence that suppresses $S c c d c 24$ has a discernible effect on the overall morphology of $S$. cerevisiae, it was used to transform some $S$. cerevisiae strains. Wild-type cells (TD4) were transformed with plasmid pLY005 containing the $C$. albicans cloned sequence or the vector 


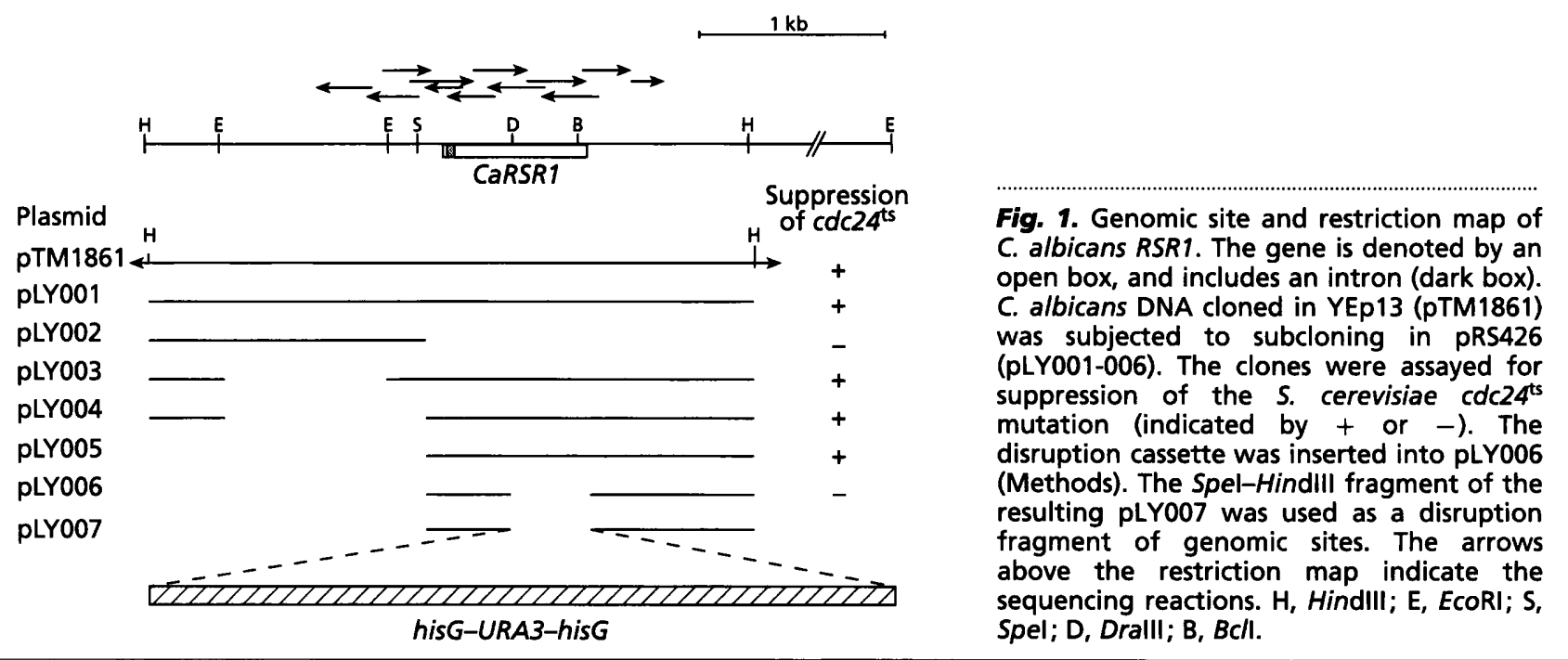

(a)

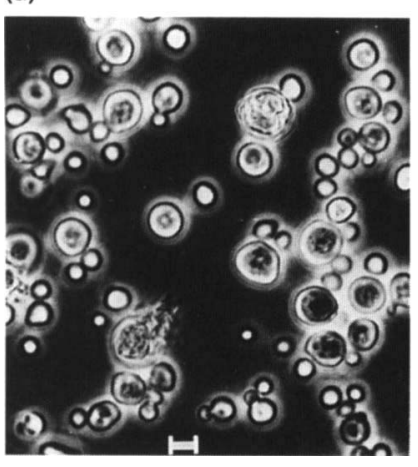

(b)

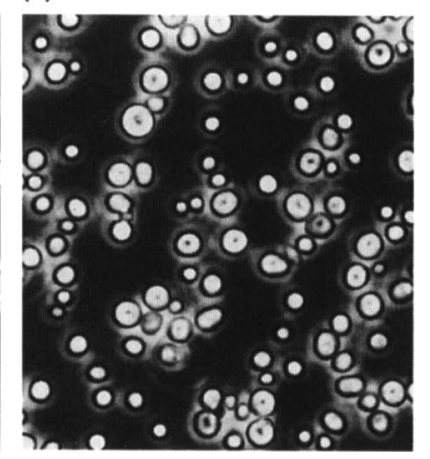

Fig. 2. Effect of CaRSR1 on cell size of an S. cerevisiae cdc42 mutant. Cells of $S$. cerevisiae DJTD2-16D transformed with (a) pTM1861 (CaRSR1) and (b) YEp13 vector were plated on SCleucine and incubated at $26^{\circ} \mathrm{C}$ for $3 \mathrm{~d}$. Cells were suspended in SC medium and observed by phase contrast microscopy. Bar, $5 \mu \mathrm{m}$.

pRS426. Some morphological effect induced by the presence of pLY005 was noticed in wild-type S. cerevisiae but the effect was minor. Microscopic examination of the cells did not reveal significant differences in cell size or shape. Very large cells that comprise less than $1 \%$ of cells sampled were detected in strains transformed with pLY005 or pRS425. The normal ovoid structure was evident among the cells transformed with the vector, whereas the cells transformed with pLY005 were more spherical.

CDC24 and CDC42 interact genetically and according to more recent results the proteins they encode interact physically (Bender \& Pringle, 1989; Zheng et al., 1994, 1995). Therefore, it was of interest to test the cloned C. albicans sequence that suppresses the $S c c d c 24$ mutation for its effect on an $S$. cerevisiae cdc42-1 mutant. The colonies formed by these transformants were very small. The cells were found to vary considerably in size and included large cells, some of which disintegrated during microscopic examination (when resuspended in SC medium; Fig. 2). This instability was not seen in cells transformed with vector sequences only. Thus, the cloned suppressor of $S c c d c 24$ did not appear to be the $C$. albicans functional homologue $S c c d c 42$.

\section{Sequence of the C. albicans suppressor of Sccdc24}

The C. albicans gene was sequenced (Fig. 3) and the deduced sequence indicated that the C. albicans suppressor of $S c c d c 24$ encodes a Ras-related protein of 248 amino acids (Fig. 4). The deduced protein is most similar to that encoded by $S$. cerevisiae RSR 1 (Bender \& Pringle, $1989 ; P=3 \cdot 8 \mathrm{e}-89$ ). The gene, designated CaRSR1, is deduced to encode a protein shorter by 24 amino acids than that encoded by $S c R S R 1$ and the proteins are $56 \%$ identical. CaRSR1 potentially includes a short exon of seven nucleotides followed by an intron of 74 nucleotides and a second exon of 737 nucleotides. The deduced splice junctions are identical to those that occur in $S$. cerevisiae and seen in other C. albicans genes (Langford et al., 1984; Smith et al., 1988). The region located between nucleotides -242 and -37 consists of $80 \%$ AT, and two clear TATA boxes (at -64 and -56$)$ are evident. It is likely that this region may therefore represent the upstream activating sequence of CaRSR1. DNA motifs which serve as $3^{\prime}$-end signals of mRNA in S. cerevisiae (Guo \& Sherman, 1995; Russo et al., 1991, 1993) can be found downstream of the TGA stop codon of CaRSR1. Four suggested efficiency element motifs (TATATATA, TATGTA, TATATA, TATGTA) are located some 36-156 nucleotides downstream of the termination codon. They are followed by a suggested positioning element motif (AATAAA) and a major poly $(A)$ site $(\mathrm{CA})$ typical of $3^{\prime}$-end signals.

The deduced CaRsr1 protein is very similar to Ras superfamily proteins in regions important for GTP binding, effector interaction and membrane attachment (Fig. 4; reviewed by Lowy \& Willumsen, 1993; Valencia et al., 1991). Both S. cerevisiae and the deduced C. albicans Rsr 1 proteins are related to the Rap family and share with Rap proteins most of the amino acid residues 
1 AAG AAA AGT AAA GCA TAT TGA GTA AAT GIT ATC GGT TTA TTT AGT TGA AAG AAA CGC GTT 61 TAT TTT TAG GT TGT GTG TGT AAA ACA AAA ATT GAA GAG AAT GTT TAG TTT TTA ATT TTT 121 CGT CTT CTG TGT TTT CTC GTC AAT GTT AAA CAA GTG TGA AAT TGG GGT TAG ATA GGT GTT 181 ATT ACT ACT ATC ATT TTC TCG TTP TAC AAA TAA AAT ACA AAT TTC TAT TTG ACC CAC TGT GTA GTA ATG GCA AAT CAT TAT TCA AAA GAC CTG AGT CGT TTT CTT GTA TTT ACA AAT 301 TAA CAA AAG ACG AAT TTA TTC TAA TTT TAC TCG TAG TAA AAA TTC CAC ATA AAT TTT AAT 361 GCC AAC CTC TCT TGG CCC TGA ATT TTG AAT TCA TGC AGT GCT GGT GGT AGT AGT GGA TTC 421 TCT TTC TGA AAA AAA AAA AAT AAA AAA GTA CGT GTT ACA TIG ATG CTT CTT AAT CGA TTA 481 ATA CAA TTA AAA TAT TAT TAT TTA TCA CTC CCA CCA AAA CAG CAA AAA AAG AAA AGC AAA SpeI

AAA AAG AAA AGC AAA ACA CTA GTC AAC AGA GAA AAA AAA AAC ACC AGA AAA AAA ATA GTA

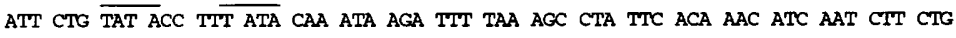
TCA GAT TIC AAT GAG AGG TAT GTA GAT TCA ACA AAA GCC CGT TAC ACT TET ATT TCA ATA met arg a

ACC TTA TAT ACT AAC TTR TET TTT GTC ACA GAT TAT AAA GTC GTA GTA TTG GGT GCT GGT sp tyr lys val val val leu gly ala gly

GGG GTA GGT AAA TCC TCA ATC ACC GTG CAA TTT GTC CAG GGT GTA TAC GTC GAA AGT TAC gly val gly lys ser ser ile thr val gln phe val gln gly val tyr val glu ser tyr

GAC CCT ACA ATT GAA GAC TCC TAT AGA AAA CAA ATC GAA GTG GAT GGC AGG GCT TGT GAT asp pro thr ile glu asp ser tyr arg lys gln ile glu val asp gly arg ala cys asp

CTA GAG ATT TTA GAT ACA GCA GGG GTG GCA CAA TTC ACA GCC ATG AGA GAA TTG TAC ATT leu glu ile leu asp thr ala gly val ala gln phe thr ala met arg glu leu tyr ile

AAA AGT GGT AAA GGG TTC TTA TTG GTG TAC TCT GTC ACC GAT`GAA AAT TCG CTT AAA GAA lys ser gly lys gly phe leu leu val tyr ser val thr asp glu asn ser leu lys glu

TTA TTA GCA CTT CGT GAA CAA GTG TTG AGA ATA AAA GAT AGT GAC AAT GTC CCT ATG GTA leu leu ala leu arg glu gln val leu arg ile lys asp ser asp asn val pro met val

TTG GTT GGG AAC AAG TGT GAT TTA GAA GAT GAC CGT GTT TTA AGT ATA GAG GAT GGG GIG leu val gly asn lys cys asp leu glu asp asp arg val leu ser ile glu asp gly val

AAA GTG AGT CAA GAT TGG GGA TTA GTA CCA TTC TAT GAA ACA AGT GCC ATG TAC AAA ACA lys val ser gln asp trp gly leu val pro phe tyr glu thr ser ala met tyr lys thr

AAT GTG GAT GAA GCG TTC ATT GAT GTT GTC AGA CAA ATC ATG AGA AAA GAA GCC GCT ATC asn val asp glu ala phe ile asp val val arg gln ile met arg lys glu ala ala ile

AGT GCC GAA AAG AAA CAA CAA AAA GAA TTA CAA AAA CAA CAA CAG CAA CAG CAG CAA GAA ser ala glu lys lys gln gln lys glu leu gln lys gln gln gln gln gln gln gln glu

CAA GAT GCT GAA GGA CAA CAA CAA CAA CAG AAA TCA GGA AAA TCC AAA TCG TCT GCA ACA gln asp ala glu gly gln gln gin gln gln lys ser gly lys ser lys ser ser ala thr

AAA GAT GCA ACA GCA GAT GGC CAA ACA GAT GTC AAT GCC AGA TTG AAA CAA TCA AT gln lys asp ala thr ala asp gly gln thr asp val asn ala arg leu lys gln ser ile BCII

AAT GAT CAC CCA AAG TCT AGC TCA GGA AGC AAG TTC TGC ACA ATT ATT TGA CCC AAT CAA asn asp his pro lys ser ser ser gly ser lys phe cys thr ile ile OPA

TCA ATC AAT CAA TCA AAT AAT ATA TCT ATA TAT ATA TGT ATT AGA GTA ATT TIT TTT TCT TGG AGG GTT AAG ACC CIT TAT ATA ATT TCT AAT TAA TIT AAA GGT TTA AAT GAT TIT TIA CAA ATA AGG GAA TTG ATC TCT ATG TAA GAA TAA AAT GGA GTT GGT GAA GAG ATT TGA CAT ACC CAA TGT ACA AAT TCA AGT CAC TTT TCC CCC TCA AAA AAA TAT AGA CCG TGT ATG TTC CTG AAA AGT TCA AGA TTT TAA TTT GCC ACG GGG AGT AAA GTT CGA AAT AAT GAA AGG ACC AAG TAA TCT AGT AGA GTT GAC TIT GTG TTA TTG TTA AAC AAT TAC ACT ACT TTA CAA TAG TAG TAA ACT TTT ATG TCA GTA CGT AAT ATA TAC ATT GCA AGA AAT OGA AAT CGT AAA
Fig. 3. CaRSR1 DNA and deduced protein sequences. Two potential TATA sequences are overlined. The intron is underlined. Its splicing conserved motifs are indicated by dots. Putative 3 '-end-forming signals of mRNA, i.e. efficiency elements, a positioning element and the major site of polyadenylation, are indicated by a double underline. Spel and $B C / l$ restriction sites are indicated. The location in which the synthetic $B C / l$ site was introduced to yield pLY006 is indicated by an asterisk. For motif details see Results.

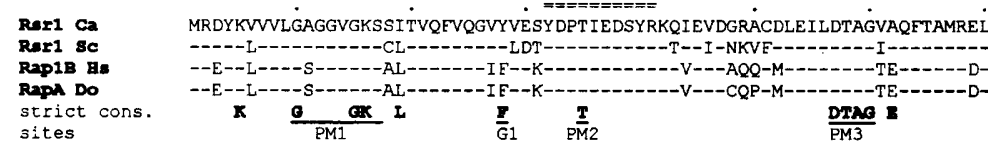
sites

Ror1 Ca Rer1 sc Rapis B Rapin Do strict cons. sites

Rarl Ca

Rer1 8c

ap18 a:

Rapa Do

strict cons.

sites

Rarl Ca

$\operatorname{Rar1}$ sc

Rapis $\mathrm{B}$

Rapa Do

strict cons.

sites

70

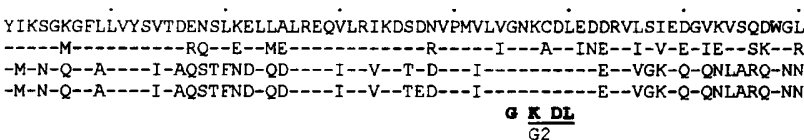

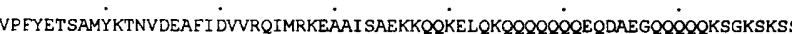
------LIRS----V-V-L----I-N-MESV-V-DARNQS-QFSKIESPSTRLPSSAK-DTKQSNNK CA-L-S--KS-I--N-I-Y-L----N--TPVPGKAR-KSS

CA-L-S--KS-I--N-I-Y-L----N--APVEKCK--KSQ

I ga $v$

QKDATADGQTDVNARLKQSINDHPKSS SGSKECTII SSKGLYNKSS-GQAKVKOSTPV-EKH-P-HAVPKSGSSNRTGI SATSQQKKKKKNAST---I
Fig. 4. Amino acid sequence alignment of the deduced $C$. albicans Rsr1 (this work), $S$. cerevisiae Rsr1 (Bender \& Pringle, 1989), human Rap1B (Matsui et al., 1990) and Discopyce ommata RapA (Ngsee et al., 1991). The coordinates for CaRsr1 are indicated. Dashes indicate identity with CaRsr1. Blanks indicate gaps inserted to maximize alignment of the sequences. Amino acids strictly conserved in the Ras superfamily (Valencia et al., 1991) are indicated by bold letters. Phosphate/Mg-binding (PM) and guanine-binding $(\mathrm{G})$ residues as well as the C-terminus ('term') are indicated by a line. The putative effector region is overlined by broken double lines. 
that participate in nucleotide binding, with a few exceptions of residues 11 and 28-31. Rap and Ras families share the effector-binding domain (residues 32-40). Rap and Rsr proteins share some distinctive features (non-glutamine at residue 61, uncharged residue at position 63), in a region (residues 59-65) that forms loop L4, important for the interaction with the GTPaseactivating protein. Alanine 62 of both Rsr1 proteins seems unique. The deduced C-terminus motif of CaRsr1, CTII, most strongly resembles the CaaL $(a=$ aliphatic residue) motif of $\mathrm{Rap}$ and $\mathrm{R}$ ho protein families (for a review, see Schafer \& Rine 1992), which is modified by a geranylgeranyl moiety required for association with membranes.

The C-terminal extension of the Ras superfamily proteins (residue 167 up to the C-terminus motif) is highly variable. It may be mobile, sticking out of the cytoplasmic globular GTP-binding domain, and may act as a flexible spacer between this domain and the membrane-bound C-terminus (Valencia et al., 1991). ScRsr1 and the deduced CaRsr1 have a longer C-terminal extension than Rap proteins from different origins. The CaRsr1 variable region is glutamine-rich (19 out of 78 residues). A 36-amino-acid inner stretch $(175-210)$ is highly hydrophilic and includes two polyglutamine (seven and five residues) stretches. The low frequency of cytosine among the first nucleotides of codons of CaRSR1, except for glutamine codons (CAA, CAG), suggests a conservation of polyglutamine in CaRsr1. Polyglutamine stretches were shown to act as transcriptional activation domains (Courey et al., 1989). The polyglutamine of the deduced CaRsr1 may have a role in protein-protein interactions, as suggested for other proteins (Burke et al., 1996; Stott et al., 1995).

\section{Disruption and reintroduction of the CaRSR1 gene}

In an attempt to elucidate the physiological role of CaRSR1, C. albicans $r s r 1 / r s r 1$ strains were constructed. This was performed by gene disruption using the method of Alani et al. (1987) and adapted for C. albicans by Fonzi \& Irwin (1993). This method allows the repeated use of $U R A 3$ selection, which is necessary to disrupt the two alleles of a given gene in C. albicans. A disruption vector was constructed as described in Methods. The deletion of $59 \%$ of the CaRSR1 ORF (corresponding to amino acid residues 87-233) covers nearly half of the guanine-binding domain and most of the C-terminal extension. The $5.4 \mathrm{~kb}$ SpeI-HindIII disruption fragment was used to transform RSR1/RSR1 strain CAI4 (Table $1)$. $\mathrm{Ura}^{+}$transformants (RSR1/rsr1, CAI4-10) were recovered as presumed heterozygotes. To allow the second round of disruption, $\mathrm{Ura}^{-}$cells were selected on a medium containing 5-FOA. The resulting cells of CAI4-11 were then retransformed with the same disruption fragment to yield $r s r 1 / r s r 1 \mathrm{Ura}^{+}$strains. Two $r s r 1 / r s r 1$ transformants (including CAI4-5) were subjected to phenotypic characterization with identical results.

Uracil auxotrophs $r s r 1 / r s r 1$ (including CAI4-5a) were obtained by a second round of 5-FOA selection. For

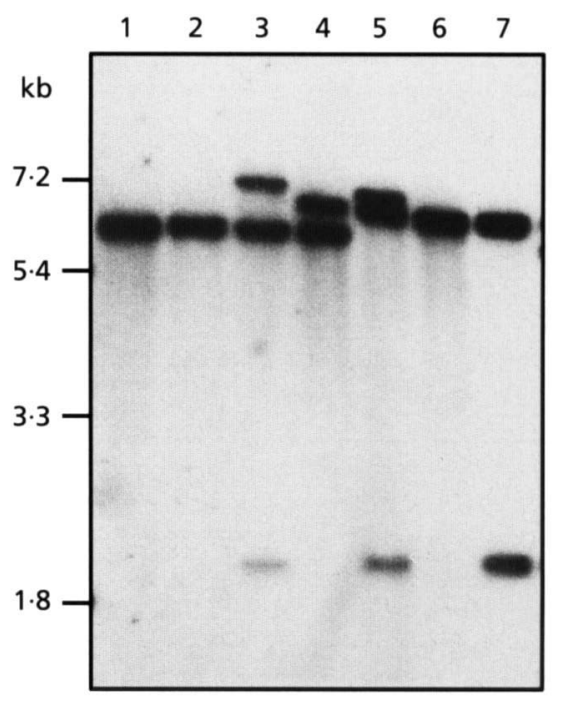

Fig. 5. Disruption and reintroduction of the CaRSR1 gene. Southern analysis with the CaRsr1 fragment (1.8 kb Spel-HindIII fragment of pLY005 insert) as the probe. C. albicans DNA digested with ECORI was from the following strains (full relevant genotypes). Lanes: 1, SC5314 (RSR1/RSR1); 2, CAl4 (RSR1/RSR1); 3, CAl4-10 (RSR1/rsr1A::hisG-URA3-hisG); 4, CAl411 (RSR1/rsr1A::hisG); 5, CAI4-5 (rsr1A::hisG-URA3-

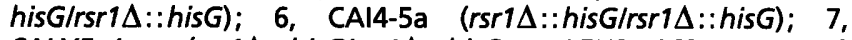
CALY5a1 (rsr1 $1:$ :hisG/rsr1A::hisG LEU2::RSR1 URA3 CaARSILEU2).

reintroduction of the CaRSR1 gene into these $r s r 1 / r s r 1$ disrupted strains, a plasmid containing CaRSR1 (pLY008) was directed into the LEU2 locus. This $8.6 \mathrm{~kb}$ $K p n I$ fragment was employed to transform the $r s r 1 / r s r 1$ strains to $\mathrm{Ura}^{+}$. All the disruptions and the reconstitution of CaRSR1 were verified by Southern analysis of EcoRI-digested genomic DNA, using a $1.8 \mathrm{~kb}$ SpeIHindIII fragment of pLY005 as a probe (Fig. 5): $6.2 \mathrm{~kb}$ bands indicate wild-type alleles (lanes 1-4). The disrupted allele is longer, split into two bands $(7 \cdot 3$ and $2 \cdot 2 \mathrm{~kb}$ ) as expected from the presence of an EcoRI site in the URA3 gene (lanes 3 and 5). The loop-out allele is expected to be $6.9 \mathrm{~kb}$ but it lacks this internal site (lanes 4-7). The reintroduced allele is represented by a new $2.2 \mathrm{~kb}$ band as expected from a fragment starting at the EcoRI site $5^{\prime}$ to the SpeI site, and ending at the EcoRI site of the pCA-1 vector (lane 7).

All phenotypic assays were performed with uracil prototrophic strains (RSR1/RSR1, RSR1/rsr1 and $r s r 1 / r s r 1$ ) and, when required, with CAF2-1 (RSR1/ RSR1) as a control having one URA3 allele, and with the $R S R 1$ reconstituted strains including CALY5a1.

\section{CaRSR1 is involved in yeast cell morphogenesis, is required for polar bud site selection, and affects the maximum cell density}

Wild-type and Carsr1 mutants were grown on solid or in liquid medium, in YPD or in SC (with or without uridine), and at different temperatures $\left(24\right.$ or $30^{\circ} \mathrm{C}$ ). 


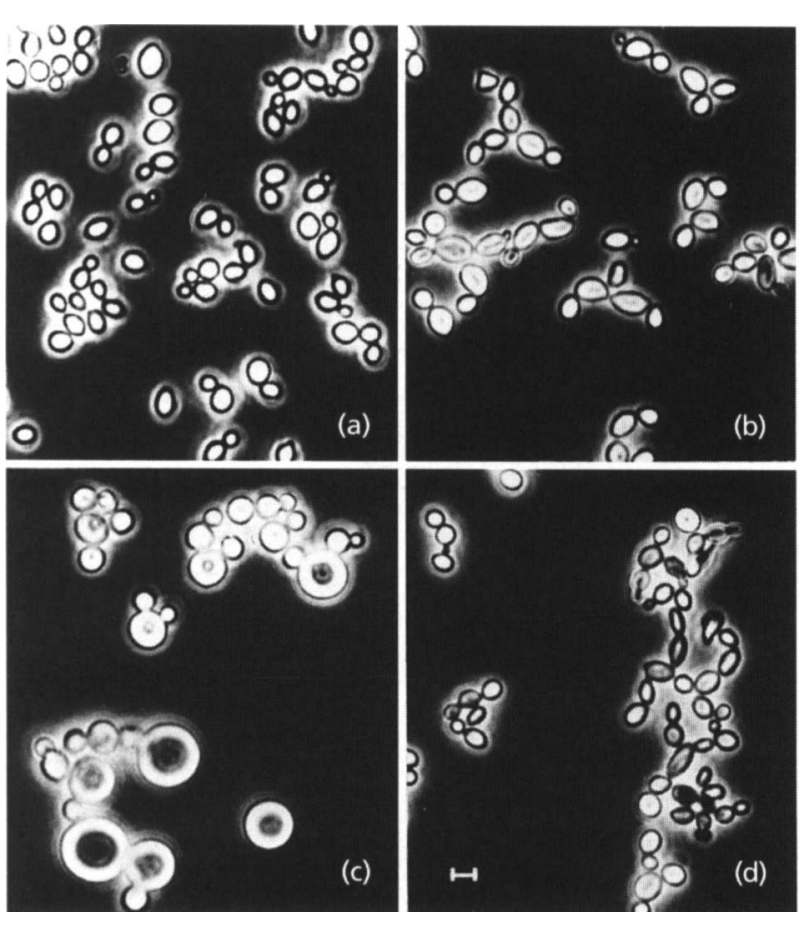

Fig. 6. Morphology of $C$. albicans strains. Cultures were grown in YPD, agitated at $30^{\circ} \mathrm{C}$ for $21 \mathrm{~h}$, to stationary phase. Cells were fixed with SDS/formalin and observed by phase contrast microscopy. (a) SC5314 (RSR1/RSR1); (b) CAl4-10 (RSR1/rsr1); (c) CAI4-5 (rsr1/rsr1); (d) CALY5a1 (rsr1/rsr1 RSR1). Bar, $5 \mu \mathrm{m}$.

Cell shape was examined microscopically. Under all the different conditions, homozygote cells $(r s r 1 / r s r 1)$ were more heterogeneous in size and shape than wild-type, heterozygote (RSR1/rsr1) or reconstituted ( $r s r 1 / r s r 1$, $R S R 1)$ strains. The cells of the homozygote disruptant were larger and tended to be spherical while cells of the wild-type and the heterozygotes were ovoid (Fig. 6). The loss of CaRSR1 leads to a more spherical shape. Therefore, it appears that CaRSR1 is involved in the polar expansion of the surface of the yeast phase cells of C. albicans.

The $S$. cerevisiae RSR1 gene is required for normal bud site selection in both haploid and diploid cells (Bender \&

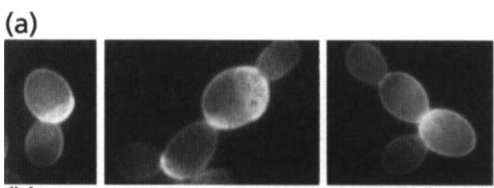

(b)
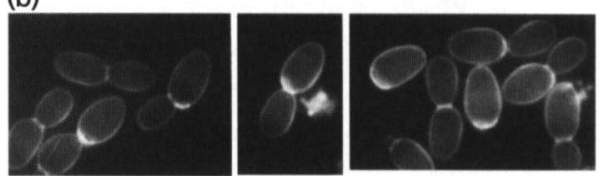

(c)
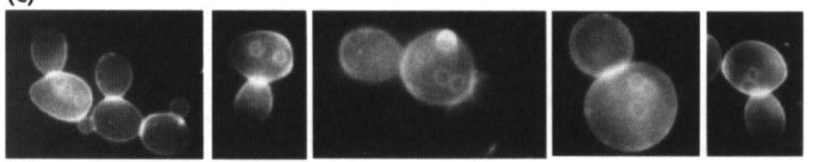

(d)

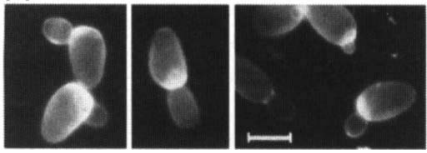

Fig. 7. Budding location of $C$ albicans strains. Calcofluorstained cells of (a) SC5314 (RSR1/RSR1), (b) CAl4-10 (RSR1/rsr1), (c) CAl4-5 (rsr1/rsr1) and (d) CALY5a1 (rsr1/rsr1 RSR1). Bar, $5 \mu \mathrm{m}$.

Pringle, 1989). The effect of CaRSR1 on the budding pattern of C. albicans was examined (Methods). The wild-type strain SC5314 and the heterozygote (RSR1/ rsr1) budded exclusively at the cell poles (Table 2; Fig. 7). In most of the cells which had a total of at least two daughter cells (identified as buds or bud scars), cell division events occurred in one pole. In cells that budded in both poles, a preference for one pole was noticed since the numbers of bud scars at each pole were not similar (data not shown). In $r s r 1 / r s r 1$, the budding location was scattered over the entire cell surface. Reintroduction of the CaRSR1 gene in CAI4-5a restored the polar budding pattern. Therefore, CaRSR1 is required for defining a distinct pattern of budding in C. albicans. The normal pattern is a polar one, as seen in the wild-type and all heterozygotes of CaRSR1.

When cells were grown in YPD broth at $30^{\circ} \mathrm{C}$, the maximum cell density of the strains was different. The cell density of SC5314 (wild-type) and CAF2-1 (URA3/

Table 2. Bud site selection in C. albicans strains

Only cells that budded at least twice were scored. See Methods for details.

\begin{tabular}{|llccc|}
\hline \multirow{2}{*}{ Strain } & $\begin{array}{l}\text { Relevant } \\
\text { genotype }\end{array}$ & \multicolumn{2}{c|}{ Budded cells (\%) } & Cells (total) \\
\cline { 3 - 4 } & & Polar & Non-polar & \\
\hline SC5314 & RSR1/RSR1 & 100 & 0 & 208 \\
CAI4-10 & RSR1/rsr1 & 99 & 1 & 272 \\
CAI4-5 & $r s r 1 / r s r 1$ & 34 & 66 & 341 \\
CALY5a1 & $r s r 1 / r s r 1$ RSR1 & 97 & 3 & 297 \\
CALY5a20 & $r s r 1 / r s r 1$ & 32 & 68 & 320 \\
\hline
\end{tabular}




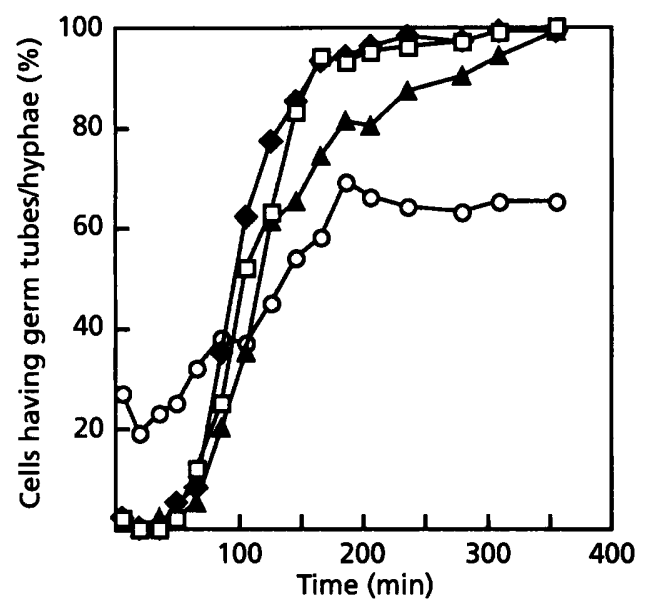

Fig. 8. Germ tube formation by $C$. albicans in Lee medium at $37^{\circ} \mathrm{C}$. The results presented are from one of two consistent repeats of the experiment. For details see Methods. $\square$, SC5314 (RSR1/RSR1); $\diamond$, CAF2-1 (RSR1/RSR1); $\triangle$, CAI4-10 (RSR1/rSr1); O, CAI4-5 (rsr1/rsr1).

ura $3 \Delta$ ) was $8.4 \times 10^{8}$ and $7 \cdot 0 \times 10^{8}$ cells $\mathrm{ml}^{-1}$, respectively. The maximum cell density reached by the heterozygote was $5.3 \times 10^{8}$ cells $\mathrm{ml}^{-1}$ but a maximum cell density of only $1.5 \times 10^{8}$ cells $\mathrm{ml}^{-1}$ was reached by the homozygote disruptants. Similar differences were observed after growing the strains in SC-uracil broth at $26^{\circ} \mathrm{C}$. Therefore, CaRSR1 might be involved, in a dose- dependent manner, in determining the maximum cell density that can be reached.

\section{CaRSR1 is involved in germ tube formation and in hyphal elongation}

CaRSR1 affects morphogenesis and bud site selection, suggesting that $C a R S R 1$ is involved in polar growth and polar budding of the yeast phase cells of $C$. albicans. To address the question of whether yeast budding and hypha development are controlled by a common pathway we attempted to determine the effect of disruption of CaRSR1 on germ tube formation and hypha elongation. Cells were grown under conditions inducing yeast growth (Lee agar at $26^{\circ} \mathrm{C}$ ) for $45 \mathrm{~h}$. Unlike the SC5314 wild-type, CAF2-1 (URA3/ura3) or the heterozygote CAI4-10 (RSR1/rsr1), the homozygote disruptant $r s r 1 / r s r 1$ developed some hyphae under conditions where the yeast-mycelium transition does not normally occur. To verify that the wild-type and heterozygote strains can undergo this transition, cells of these strains were transferred to medium that induces hypha development (Lee broth at $37^{\circ} \mathrm{C}$; see Methods). The percentage of yeast cells forming germ tubes or developing hyphae was monitored (Figs 8 and 9). All the strains began germ tube formation after a lag of about $50 \mathrm{~min}$. Maximum germination was achieved by $200 \mathrm{~min}$ with the exception of the heterozygote, which required $350 \mathrm{~min}$ to reach this maximum. However, cells of CAI4-5 $(r s r 1 / r s r 1)$ responded slowly and no
SC5314
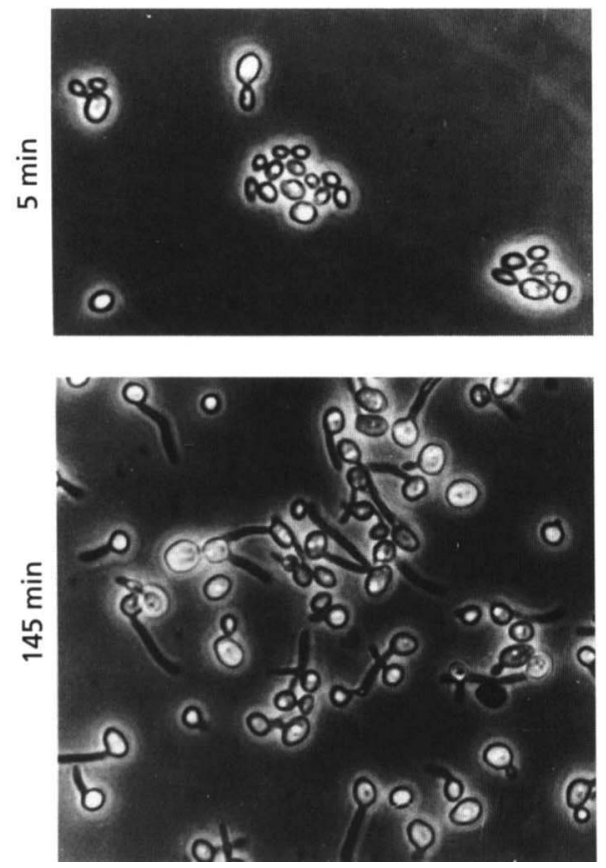

CAI4-10
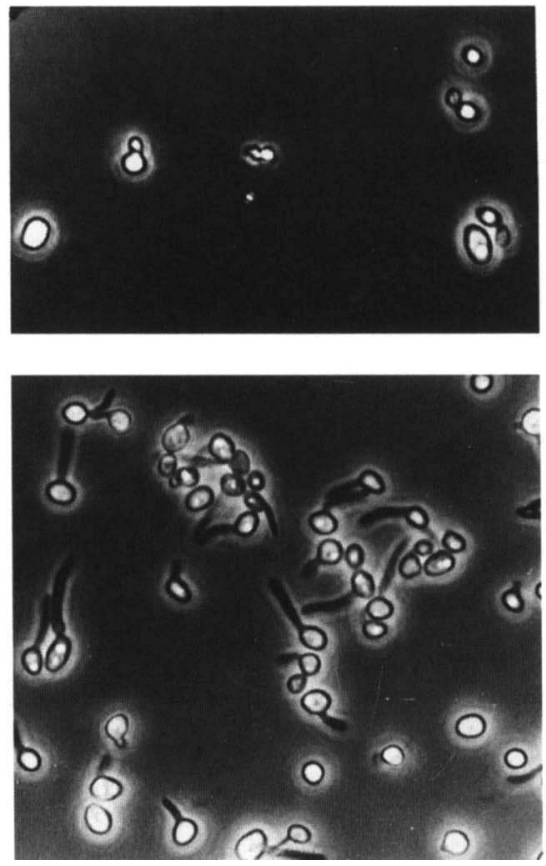

CAI4-5
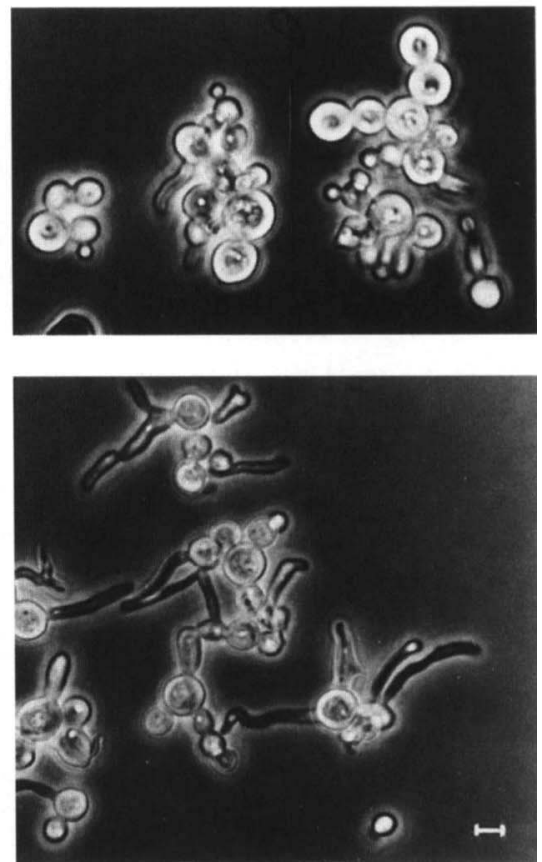

Fig. 9. Germ tube formation. C. albicans cells were grown under conditions inducing yeast phase growth and observed 5 and $145 \mathrm{~min}$ after being transferred to conditions inducing germ tube formation (Methods). SC5314, RSR1/RSR1; CAI4-10, RSR1/rsr1; CAl4-5, rsr1/rsr1. Bar, $5 \mu \mathrm{m}$. 


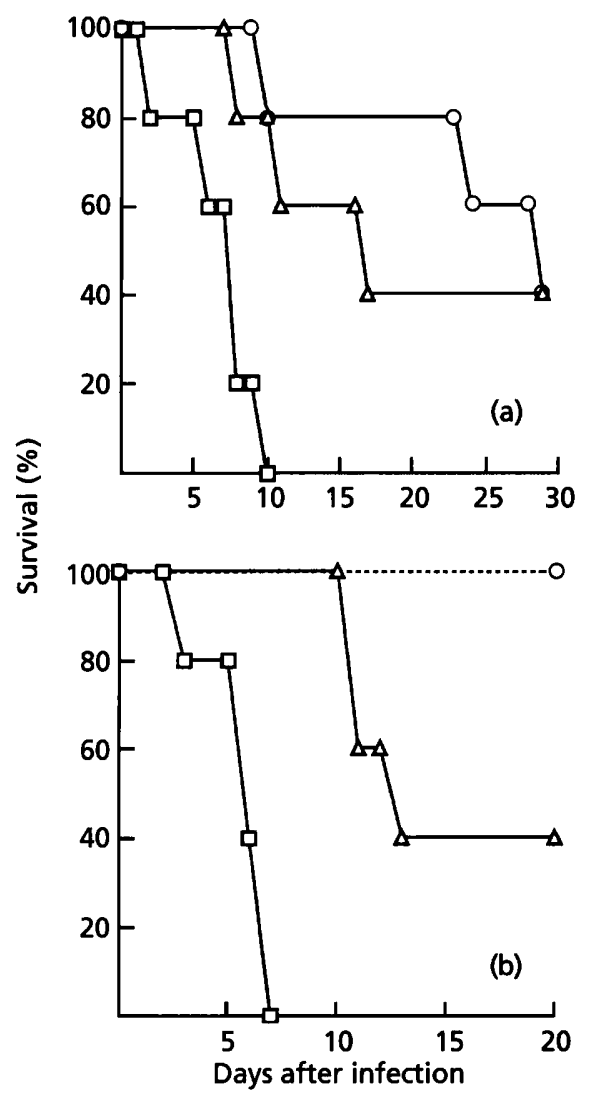

Fig. 10. Survival curves of mice $(n=5)$ infected with $C$. albicans strains (see Methods for details). (a) Immunocompetent mice; (b) neutropenic mice. $\square$, SC5314; $\triangle$, CAI4-10; O, CAI4-5.

more than $45 \%$ of cells formed germ tubes under the same experimental conditions, while the other strains reached $100 \%$ germination.

Hyphal growth was also affected in the homozygote disruptant. The maximum hyphal length after $22 \mathrm{~h}$ at $37^{\circ} \mathrm{C}$ was $240 \mu \mathrm{m}$ and $280 \mu \mathrm{m}$ for the wild-type SC5314 and CAF2-1, respectively. The length of the hyphae of CAI4-10 (RSR1/rsr1) during the same time period was $160 \mu \mathrm{m}$, and that of the homozygote disruptant CAI4-5 (rsr $1 / r s r 1)$ only $60 \mu \mathrm{m}$. These results suggest that CaRSR1 is involved in both germ tube emergence and in hyphal elongation. The differences cannot be interpreted as a response to the dosage of URA3 since CAF2-1, like CAI4-10, contains one URA3 allele. Taken together, our results suggest that the same gene that affects yeast cell shape affects germ tube and hypha development.

When the signal used to induce germination was serum medium, CaRSR1 was not found to affect significantly the ability to form germ tubes. Some $87 \%$ of the cells of the homozygote disruptant (CAI4-5) germinated by $85 \mathrm{~min}$, a time in which $99 \%$ of the wild-type (SC5314) and $95 \%$ of the heterozygote (CAI4-10) cells had germinated. However, comparison of the same three strains after $25 \mathrm{~min}$ in serum medium revealed that the homozygote disruptant had a longer lag in its response to the germinating conditions. Only $15 \%$ of cells germinated whereas $30 \%$ of cells of the heterozygote and wild-type formed germ tubes during this time. Thus, the effect of CaRSR1 on germination under these conditions appears to be primarily in response to the signal that initiates germination rather than germ tube emergence.

\section{$R S R 1$ is required for virulence}

The importance of the transition from the yeast form to the mycelial form for virulence has been discussed for many years. The application of new molecular biological methods that offer an opportunity to introduce precise mutations in the otherwise isogenic background of the strains used allows more accurate assessment of the importance of specific genes for virulence and the importance of various developmental phases such as germ tube formation and hyphal development for the infection process. Therefore, we examined the effect of CaRSR1 on virulence. Infection of both immunocompetent and neutropenic mice with the wild-type, heterozygote CaRSR1/Carsr1 and the homozygote disruptant indicated a marked reduction of virulence in a gene-dose-related manner (Fig. 10). Thus, CaRSR1 appears to be required in the infection process and can be regarded as a virulence gene of $C$. albicans.

\section{DISCUSSION}

The objective of this study was to search for common components of polar processes of C. albicans in the yeast form and in the hyphal form. The candidates for the polarity components were genes of $C$. albicans which are functional homologues of genes of $S$. cerevisiae involved in either polarity establishment or bud site selection. A C. albicans gene, CaRSR1, was isolated as a suppressor of a $c d c 24^{\text {ts }}$ mutation of $S$. cerevisiae. Cdc24 of $S$. cerevisiae is required for polarity of bud shape, budding location determination (Sloat et al., 1981) and mating (Chenevert et al., 1994). The cloned C. albicans gene is most similar to RSR1 (BUD1) of $S$. cerevisiae (Bender \& Pringle, 1989).

\section{CaRSR1 is involved in polarity of budding and yeast phase cell morphogenesis}

Unlike wild-type $C$. albicans cells which bud at cell poles, $r s r 1 / r s r 1$ cells bud randomly over the cell surface. Moreover, the $r s r 1 / r s r 1 C$. albicans strains display a phenotype of heterogeneous cell size and shape. They tend to be large spherical cells. A phenotype of large spherical cells is known for several budding mutants of S. cerevisiae, i.e. cdc24 (Hartwell et al., 1973; Sloat et al., 1981), cdc42, cdc43 (Adams et al., 1990), bem1, bem2 (Bender \& Pringle, 1989) and $\operatorname{cln} 1 c \ln 2$ and $b u d 2$ (Benton et al., 1993), and also for Schizosaccharomyces pombe homologues of these proteins (Chang et al., 1994; Fukui et al., 1986). It is attributed to a general expansion of the cell cortex. CaRSR1 is concluded to be required for polar budding and to be involved in ovoid cell mor- 
phogenesis. S. cerevisiae Rsr1 has been demonstrated to be localized throughout the cortex and suggested to be locally converted to the GTP-bound activated form at the marked bud site (Michelitch \& Chant, 1996). It is plausible that a similar mechanism underlies the role of CaRsr1 in controlling cell shape.

\section{The budding pathway of $C$. albicans resembles that of $S$. cerevisiae}

The RSR 1 gene of C. albicans is similar in four respects to that of $S$. cerevisiae: suppression of an $S c c d c 24^{\text {ts }}$ mutation, sequence similarity, requirement for polar budding and viability of $r s r 1 / r s r 1$ deletion mutants. $C a C D C 42$, which was isolated as a suppressor of an $S c c d c 42^{\text {ts }}$ mutation (L. Yaar, J. Clifford \& Y. Koltin, unpublished), is $87 \%$ identical to ScCDC42 (Johnson \& Pringle, 1990). CaRSR1 was demonstrated to affect Sccdc42 mutant cells. This might be a consequence of the interaction of $\mathrm{CaRsr} 1$ with $\mathrm{ScCdc} 42, \mathrm{ScCdc} 24$ or with another protein that usually interacts with $\mathrm{Cdc} 42$ (which is another Ras superfamily member). All the above suggest similarity of the budding pathway in the two organisms. Schiz. pombe differs from these two yeasts by having one protein, Ras1p, involved in both the pheromone pathway and morphogenesis.

The size variability and spherical shape characteristic of the $r s r 1 / r s r 1$ mutants in C. albicans were not reported for a $S$. cerevisiae rsr $1 / r s r 1$ deletion mutant that appears to grow as wild-type but with some exceptions (Gimeno et al., 1992) buds randomly (Bender \& Pringle, 1989). The spherical shape has been reported for a Schiz. pombe RAS1 mutant (Fukui et al., 1986). CaRSR1 might therefore play a more dominant role in cell morphogenesis than its $S$. cerevisiae counterpart. This may be attributed to the limited identity of $S$. cerevisiae and $C$. albicans $\mathrm{Rsr} 1$ proteins $(56 \%$ amino acid sequence identity) in comparison with that of Cdc42 (87\% amino acid sequence identity) of the two yeasts. The differences between the variable regions of the two Rsr1 proteins (including the polyglutamine of CaRsr1) may cause interactions with different proteins. Other unshared characteristics of the two fungi cannot be ruled out as the cause of the differences.

\section{CaRSR1 is involved in the yeast-hypha transition and in hyphal length determination by a novel pathway}

We have demonstrated that CaRSR1 is required by cells grown in hypha-inducing $\left(37^{\circ} \mathrm{C}\right.$; Lee) medium for full extent and rate of germ tube emergence and for normal extent of hyphal elongation. These conditions have been shown to induce germ tube formation independently of C. albicans CST20, HST7 or CPH1 genes, which are required for hypha formation under other inducing conditions (Köhler \& Fink, 1996; Leberer et al., 1996; Liu et al., 1994). We suggest that the role of CaRSR1 in the transition of $C$. albicans from yeast to hyphal growth, under these conditions, occurs through a novel pathway of hyphal formation, different to the mycelial formation pathway which is analogous to the pseudo- hyphae/mating response pathway of $S$. cerevisiae. This pathway seems distinct from the one transducing the serum signal for yeast-hypha transition, which is almost unaffected by the disruption of the CaRSR1 gene. The presence of hyphae among C. albicans $r s r 1 / r s r 1$ disrupted yeast cells, while grown under conditions which induce growth of yeast cells, suggests that CaRSR1 might be involved in repressing hyphal growth under conditions which do not favour the yeast-hypha transition. Taken together with the reduced final densities of the mutant cells when growing as the yeast form in liquid media (YPD, $30^{\circ} \mathrm{C}$; SC-uracil, $26^{\circ} \mathrm{C}$ ), a model can be offered in which CaRsr1 is involved in transduction of signals, enhancing the yeast-hypha transition under inducing conditions (Lee broth; $37^{\circ} \mathrm{C}$ ) and repressing the transition under non-inducing conditions (Lee medium; $26^{\circ} \mathrm{C}$ ). The suggested role of CaRSR1 in transducing signals for growth phase transition, combined with its involvement in determining final cell density of cultures, might account for the reduced virulence of the disrupted C. albicans mutant. A similar reduction in virulence has been recorded for a number of genes (Bulawa et al., 1995), including CST20 (Leberer et al., 1996). The effect demonstrated in our study is not as dramatic as one would anticipate based on the fact that CaRSR1 appears to affect a pathway critical for determination of both yeast cell shape and hypha development. Since RSR1 disruption does not totally abolish the ovoid shape of cells of the yeast phase, germ tube emergence and hypha elongation, its product is suggested to be redundant or to activate another protein during both phases of growth. Partial penetrance (heterogeneous morphology) of a deletion mutation was previously observed for the $S$. cerevisiae bud emergence mutant bem1 as well (Chenevert et al., 1992).

\section{Concluding remarks}

We demonstrated that in C. albicans CaRSR 1 is required for bud site selection, and is involved in yeast phase cell morphogenesis, germ tube emergence and hypha elongation. We conclude that this gene plays a significant role in facilitating polar bud site selection and a moderate role in yeast cell morphogenesis and transition to and growth in the filamentous phase. We propose that these roles are executed by a common function of focusing cell surface growth to surface sites. The pathways might involve $\mathrm{CaCdc} 42$ interaction with Ste20-like protein kinases, such as those involved in polarity/cytoskeletal functions in growth of $S$. cerevisiae and Schiz. pombe which are independent of pseudohyphal response and pheromone response (Cla4, Cvrcková et al., 1995; Pak1, Ottilie et al., 1995; Shk1, Marcus et al., 1995).

Many questions concerning the polar processes and the role of CaRSR1 remain to be answered, such as RSR1 involvement in the CST20/HST7/CPH1 pathway of filamentous growth. Also, are there more common components, other than CaRSR1, which are shared between the polarity pathways of the yeast and hyphal phase? What are the additional cell components in- 
volved in determining ovoid cell shape, germ tube emergence and hyphal length and do they include the gene products of the C. albicans homologues of $S$. cerevisiae $C D C 24, C D C 42$ and other polarity establishment genes, or is there a functional redundancy with the unknown RAS like that demonstrated for $S$. cerevisiae RSR1 (Morishita et al., 1995; Ruggieri et al., 1992) ? It is likely that C. albicans will display a higher degree of complexity than $S$. cerevisiae and that additional components involved in these morphogenetic processes will be identified.

\section{ACKNOWLEDGEMENTS}

We would like to thank Melinda Hauser and Dr Jeff Becker (University of Tennessee) for virulence tests, D. I. Johnson (University of Vermont) for $S$. cerevisiae strains, A. Bender (Cornell University) for plasmids, and W. A. Fonzi (Georgetown University) for the C. albicans strain and plasmid.

\section{REFERENCES}

Adams, A. E. M., Johnson, D. I., Longnecker, R. M., Sloat, B. F. \& Pringle, J. R. (1990). CDC42 and CDC43, two additional genes involved in budding and the establishment of cell polarity in the yeast Saccharomyces cerevisiae. J Cell Biol 111, 131-142.

Alani, E., Liang, C. \& Kleckner, N. (1987). A method for gene disruption that allows repeated use of URA3 selection in construction of multicopy disrupted yeast strains. Genetics 116, 541-545.

Bender, A. (1993). Genetic evidence for the roles of the bud-siteselection genes BUD5 and BUD2 in control of the Rsr1 (Bud1p) GTPase in yeast. Proc Natl Acad Sci USA 90, 9926-9929.

Bender, A. \& Pringle, J. R. (1989). Multicopy suppression of the $c d c 24$ budding defect in yeast by CDC42 and three newly identified genes including the ras-related gene RSR1. Proc Natl Acad Sci USA 86, 9976-9980.

Benton, B. K., Tinkelberg, A. H., Jean, D., Plump, S. D. \& Cross, F. R. (1993). Genetic analysis of $C \ln / C d c 28$ regulation of cell morphogenesis in budding yeast. EMBO J 12, 5267-5275.

Boeke, J. D., Lacroute, F. \& Fink, G. R. (1984). A positive selection for mutants lacking orotidine- 5 -phosphate decarboxylase activity in yeast: 5-fluoro-orotic acid resistance. Mol Gen Genet 197, 345-346.

Bulawa, C. E., Miller, D. W., Henry, L. K. \& Becker, J. M. (1995). Reduced virulence of chitin-deficient mutants of Candida albicans. Proc Natl Acad Sci USA 92, 10570-10574.

Burke, J. R., Enghild, J. J., Martin, M. E., Jou, Y.-S., Myers, R. M., Roses, A. D., Vance, J. M. \& Strittmatter, W. J. (1996). Huntingtin and DRPLA proteins selectively interact with the enzyme GAPDH. Nat Med 2, 347-350.

Cannon, R. C., Jenkinson, H. F. \& Shepherd, M. G. (1990). Cloning and expression of Candida albicans $A D E 2$ and proteinase genes on a replicative plasmid in C. albicans and in Saccharomyces cerevisiae. Mol Gen Genet 235, 453-457.

Chaffin, W. L. (1984). Site selection for bud and germ tube emergence in Candida albicans. J Gen Microbiol 130, 431-440.

Chang, E. C., Barr, M., Wang, Y., Jung, V., Xu, H.-P. \& Wigler, M. H. (1994). Cooperative interaction of $S$. pombe proteins required for mating and morphogenesis. Cell 79, 131-141.

Chenevert, J., Corrado, K., Bender, A., Pringle, J. \& Herskowitz, I. (1992). A yeast gene (BEM1) necessary for cell polarization whose product contains two $\mathrm{SH} 3$ domains. Nature 356, 77-79.
Chenevert, J., Valtz, N. \& Herskowitz, I. (1994). Identification of genes required for normal pheromone-induced cell polarization in Saccharomyces cerevisiae. Genetics 136, 1287-1297.

Christianson, T. W., Sikorski, R. S., Dante, M., Shero, J. H. \& Hieter, P. (1992). Multifunctional yeast high-copy-number shuttle vectors. Gene 110, 119-122.

Coleman, K. G., Steensma, H. Y., Kaback, D. B. \& Pringle, J. R. (1986). Molecular cloning of chromosome I DNA from Saccharomyces cerevisiae: isolation and characterization of the CDC24 gene and adjacent regions of the chromosome. Mol Cell Biol 6, 4516-4525.

Courey, A. J., Holtzman, D. A., Jackson, S. P. \& Tjian, R. (1989). Synergistic activation by the glutamine rich domains of human transcription factor Sp1. Cell 59, 827-836.

Cutler, J. E. (1991). Putative virulence factors of Candida albicans. Annu Rev Microbiol 45, 187-218.

Crrcková, A., De Virgilio, C., Manser, E., Pringle, J. R. \& Nasmyth, K. (1995). Ste20-like protein kinases are required for normal localization of cell growth and for cytokinesis in budding yeast. Genes Dev 9, 1817-1830.

Devereux, J., Haeberli, P. \& Smithies, O. (1984). A comprehensive set of sequence analysis programs for the VAX. Nucleic Acids Res 12, 387-395.

Fonzi, W. A. \& Irwin, M. W. (1993). Isogenic strain construction and gene mapping in Candida albicans. Genetics 134, 717-728.

Fukui, Y., Kozasa, T., Kaziro, Y., Takeda, T. \& Yamamoto, M. (1986). Role of a ras homolog in the life cycle of Schizosaccharomyces pombe. Cell 44, 329-336.

Gillum, A. M., Tsay, E. Y. H. \& Kirsch, D. R. (1984). Isolation of the Candida albicans gene for orotidine- 5 -phosphate decarboxylase by complementation of $S$. cerevisiae ura3 and E. coli pyrF mutations. Mol Gen Genet 198, 179-192.

Gimeno, C. J., Ljungdhal, P. O., Styles, C. A. \& Fink, G. R. (1992). Unipolar cell divisions in the yeast Saccharomyces cerevisiae lead to filamentous growth : regulation by starvation and $R A S$. Cell 68, 1077-1090.

Guo, Z. \& Sherman, F. (1995). 3'-End-forming signals of yeast mRNA. Mol Cell Biol 15, 5983-5990.

Hartwell, L. H., Mortimer, R. K., Culotti, J. \& Culotti, M. (1973). Genetic control of the cell division cycle in yeast. V. Genetic analysis of $c d c$ mutants. Genetics 74, 267-286.

Herskowitz, I., Park, H.-O., Sanders, S., Valtz, N. \& Peter, M. (1995). Programming of cell polarity in budding yeast by endogenous and exogenous signals. Cold Spring Harbor Symp Quant Biol 60, 717-727.

Hoffman, C. S. \& Winston, F. (1987). A ten minute DNA preparation from yeast efficiently releases autonomous plasmids for transformation of E. coli. Gene 57, 267-272.

Ito, H., Fukuda, Y., Murata, K. \& Kimura, A. (1983). Transformation of intact yeast cells treated with alkali cations. J Bacteriol 153, 163-168.

Johnson, D. I. \& Pringle, J. R. (1990). Molecular characterization of CDC42, a S. cerevisiae gene involved in the development of cell polarity. J Cell Biol 111, 143-152.

Köhler, J. R. \& Fink, G. R. (1996). Candida albicans strains heterozygous and homozygous for mutations in mitogen-activated protein kinase signalling components have defects in hyphal development. Proc Natl Acad Sci USA 93, 13223-13228.

Kwon-Chung, K. J. \& Bennett, J. (1992). Medical Mycology, pp. 816-817. Philadelphia, PA: Lea \& Fabiger.

Langford, C. J., Klinz, F. J., Donath, C. \& Gallwitz, D. (1984). Point 
mutations identify the conserved, intron contained TACTAAC as an essential splicing signal sequence in yeast. Cell 36, 645-653.

Leberer, E., Harcus, D., Broadbent, I. D., Clark, K. L., Dignard, D., Ziegelbauer, K., Schmidt, A., Gow, N. A. R., Brown, A. J. P. \& Thomas, D. Y. (1996). Signal transduction through homologs of the Ste20p and Ste7p protein kinases can trigger hyphal formation in the pathogenic fungus Candida albicans. Proc Natl Acad Sci USA 93, 13217-13222.

Lee, K. L., Buckley, H. R. \& Campbell, C. C. (1975). An amino acid liquid synthetic medium for the development of mycelial and yeast forms of Candida albicans. Sabouraudia 13, 148-153.

Liu, H., Köhler, J. \& Fink, G. R. (1994). Suppression of hyphal formation in Candida albicans by mutation of a STE12 homolog. Science 266, 1723-1726.

Lowy, D. R. \& Willumsen, B. M. (1993). Function and regulation of RAS. Annu Rev Biochem 62, 851-891.

Maeda, H. \& Ishida, N. (1967). Specificity of binding hexopyranosyl polysaccharides with fluorescent brightener. $J$ Biochem 62, 276-278.

Marck, C. (1988). DNA Strider: a 'C' program for the fast analysis of DNA and protein sequences on the Apple Macintosh family of computers. Nucleic Acids Res 16, 1829-1836.

Marcus, S., Polverino, A., Chang, E., Robbins, D., Cobb, M. H. \& Wigler, M. H. (1995). Shk1, a homolog of the Saccharomyces cerevisiae Ste 20 and mammalian $\mathrm{p} 65^{\mathrm{PAK}}$ protein kinases, is a component of a Ras/Cdc42 signalling module in the fission yeast Schizosaccharomyces pombe. Proc Natl Acad Sci USA 92, 6180-6184.

Matsui, Y., Kikuchi, A., Kawata, M., Kondo, J., Teranishi, Y. \& Takai, Y. (1990). Molecular cloning of $s m g$ p21B and identification of $s m g$ p21 purified from bovine brain and human platelets as smg 21B. Biochem Biophys Res Commun 166, 1010-1016.

Michelitch, M. \& Chant, J. (1996). A mechanism of Bud1p GTPase action suggested by mutational analysis and immunolocalization. Curr Biol 6, 446-454.

Mischke, D. M. \& Chant, J. (1995). The shape of things to come: morphogenesis in yeast and related patterns in other systems. Can J Bot 73 (Suppl. 1), 234-242.

Morishita, T., Mitsuzawa, H., Nakafuku, M., Nakamura, S., Hattori, S. \& Anraku, Y. (1995). Requirement of Saccharomyces cerevisiae Ras for completion of mitosis. Science 270, 1213-1215.

Ngsee, J. K., Elferink, L. A. \& Scheller, R. H. (1991). A family of raslike GTP-binding proteins expressed in electromotor neurons. $J$ Biol Chem 266, 2675-2680.

Odds, F. C., Cockayne, A., Hayward, J. \& Abbot, A. B. (1985). Effects of imidazole- and triazole-derivative antifungal compounds on the growth and morphological development of Candida albicans hyphae. J Gen Microbiol 131, 2581-2589.

Ottilie, S., Miller, P. J., Johnson, D. I., Creasy, C. L., Sells, M. A., Bagrodia, S., Forsburg, S. L. \& Chernoff, J. (1995). Fission yeast $p a k 1^{+}$encodes a protein kinase that interacts with Cdc42p and is involved in the control of cell polarity and mating. EMBO J 14, 5908-5919.

Roemer, T., Vallier, L. G. \& Snyder, M. (1996). Selection of polarised growth sites in yeast. Trends Cell Biol 6, 431-438.
Rosenbluh, A., Mevarech, M., Koltin, Y. \& Gorman, J. A. (1985). Isolation of genes from Candida albicans by complementation in Saccharomyces cerevisiae. Mol Gen Genet 200, 500-502.

Ruggieri, R., Bender, A., Matsui, Y., Powers, S., Takai, Y., Pringle, J. R. \& Matsumoto, K. (1992). RSR1, a ras-like gene homologous to $\mathrm{Krev}-1(s m g 21 A / \operatorname{rap} 1 A)$ : role in the development of cell polarity and interactions with the Ras pathway in Saccharomyces cerevisiae. Mol Cell Biol 12, 758-766.

Russo, P., Li, W.-Z., Hampsey, D. M., Zaret, K. S. \& Sherman, F. (1991). Distinct cis-acting signals enhance $3^{\prime}$ end point formation of CYC1 mRNA in the yeast Saccharomyces cerevisiae. EMBO J 10, 563-571.

Russo, P., Li, W.-Z., Guo, Z. \& Sherman, F. (1993). Signals that produce $3^{\prime}$ termini in CYC1 $\mathrm{mRNA}$ of the yeast Saccharomyces cerevisiae. Mol Cell Biol 13, 7836-7849.

Sambrook, J., Fritsch, E. F. \& Maniatis, T. (1989). Molecular Cloning: a Laboratory Manual, 2nd edn. Cold Spring Harbor, NY: Cold Spring Harbor Laboratory.

Sanger, F., Nicklen, S. \& Coulson, A. R. (1977). DNA sequencing with chain-terminating inhibitors. Proc Natl Acad Sci USA 74, 5463-5467.

Schafer, W. R. \& Rine, J. (1992). Protein prenylation genes, enzymes, targets and functions. Annu Rev Genet 30, 209-237.

Sherman, F. (1991). Getting started with yeast. Methods Enzymol 194, 3-21.

Sloat, B., Adams, A. \& Pringle, J. (1981). Roles of the CDC24 gene product in cellular morphogenesis during the $S$. cerevisiae cell cycle. J Cell Biol 89, 395-405.

Smith, H. A., Allaudeen, H. S., Whitman, M. H., Koltin, Y. \& Gorman, A. G. (1988). Isolation and characterization of a $\beta$ tubulin gene from Candida albicans. Gene 63, 53-63.

Staebell, M. \& Soll, D. R. (1985). Temporal and spatial differences in cell wall expansion during bud and mycelium formation in Candida albicans. J Gen Microbiol 131, 1467-1480.

Sternberg, N., Sauer, B., Hoess, R. \& Abremski, K. (1986). Bacteriophage P1 cre gene and its regulatory region. Evidence for multiple promoters and for regulation by DNA methylation. $J$ Mol Biol 187, 197-212.

Stott, K., Blackburn, J. M., Butler, P. J. G. \& Perutz, M. (1995). Incorporation of glutamine repeats makes protein oligomerize: implications for neurodegenerative diseases. Proc Natl Acad Sci USA 92, 6509-6513.

Valencia, A., Chardin, P., Wittinghofer, A. \& Sander, C. (1991). The ras protein family: evolutionary tree and role of conserved amino acids. Biochemistry 30, 4637-4648.

Zheng, Y., Cerione, R. \& Bender, A. (1994). Control of the yeast bud-site assembly GTPase Cdc42. Catalysis of guanine nucleotide exchange by Cdc24 and stimulation of GTPase activity by Bem3. $J$ Biol Chem 269, 2369-2372.

Zheng, Y., Bender, A. \& Cerione, R. A. (1995). Interactions among proteins involved in bud-site selection and bud-site assembly in Saccharomyces cerevisiae. J Biol Chem 270, 626-630.

Received 6 March 1997; revised 15 May 1997; accepted 27 May 1997. 